\title{
Representação Física de Dados Espaciais como Suporte à Cognição
}

\author{
Physical Representation of Spatial Data as a Support for Cognition
}

\author{
> Ivan Custódio dos Santos Souto \\ Universidade de São Paulo, Brasil \\ ivan.souto@usp.br
}

\begin{abstract}
This paper introduces the subject of spatial data representation through physical objects. The process of creation and virtual prototyping of a specific object are described, representing the data of a research about urban mobility of São Paulo metropolitan area. The process evaluation is based on its pedagogical potentialities and as a way of communicating characteristics of complex urban scenarios.
\end{abstract}

Keywords: Spatial Data; Geoprocessing; Parametric Modeling; Digital Fabrication; Data Visualization.

\section{Dados e a Cidade}

A arquitetura e o urbanismo sempre trataram da estruturação de dados e informaçóes no espaço, mesmo que de maneira analógica (Oosterhuis 2002). Geralmente no início do processo de projeto são levantados os dados considerados mais relevantes, para que se tenha uma melhor visão geral do problema, que ajude a contextualizar e direcionar as tomadas de decisão. Exemplos típicos num projeto de arquitetura incluem investigaçóes acerca do local, como atividades, fluxos e restriçóes estabelecidas pelo planejamento urbano (Vande Moere, 2005).

Segundo Manovich (2001), a diferença trazida pelo desenvolvimento das tecnologias da informação digitais está no modo como nos relacionamos com esses dados. Hoje temos uma grande quantidade de dados digitalizados e grande parte das atividades de trabalho realizadas em diversas áreas consiste na manipulação de dados (ou processamento de informaçóes) através da tela de um computador. Utilizamos com frequência ferramentas de busca para localizar dados em grandes arquivos.

O trabalho descrito nesse artigo surgiu como suporte a uma série de pesquisas e projetos de extensão universitária que tem a região metropolitana de São Paulo como tema. Dada a extensa quantidade de dados disponíveis sobre essa região, alguns temas em voga na universidade motivaram uma busca por formas de melhorar a visualização de dados referentes à cidade, tanto no suporte às atividades de projeto e pesquisa como na comunicação com agentes atuantes no cenário da metrópole. A discussão da mobilidade urbana na região e as transformaçôes da infra-estrutura urbana em função do recebimento da Copa do Mundo são alguns dos temas que surgem com frequência no meio universitário e na mídia, mobilizando a sociedade em todas as suas esferas.

A visualização de dados nesse contexto é uma forma de democratizar o acesso a informação, tornando-a atrativa e aproximando-a do público leigo. Ferramentas de visualizaçáo podem ser usadas no contato com comunidades envolvidas em projetos, embasando processos de intervenção no espaço, tornando mais claras as políticas públicas ou auxiliando a compreensão de cenários urbanos complexos.

Nesse âmbito, uma das frentes de pesquisa do grupo de estudos DIGIFAB (Tecnologias digitais de fabricação aplicadas à produção do Design e Arquitetura Contemporâneos), da Faculdade de Arquitetura e Urbanismo da USP, trata da criaçáo de objetos em que a representação de dados espaciais se dá através de sua própria forma e do tratamento das superfícies.

$\mathrm{O}$ artigo introduz ao tema da representação de dados espaciais através de objetos físicos, através de uma busca por precedentes nesse tipo de iniciativa, e descreve o processo de criação e prototipagem virtual de um objeto específico, onde foram definidas as diretrizes e discutidas os principais conceitos envolvidos. A representaçâo em imagem desse protótipo foi a base para as primeiras avaliaçóes dessa ferramenta.

\section{Diretrizes da Proposta}

Uma vez que um conjunto de dados é digitalizado e critérios sáo estabelecidos para a geração de uma geometria através deles, 
é possível convertê-los em um formato de arquivo que pode ser impresso em uma impressora 3D. Segundo Gwilt (2012), a produção de um objeto físico através da impressão $3 \mathrm{D}$ possibilita novos caminhos para a compreensão e acessibilidade de dados científicos e estatísticos. A materialização de dados digitais através da fabricação digital possibilita o contato tátil e a visualização de pontos de vista diferenciados, aproximando a geometria e os dados que representa da capacidade cognitiva humana.

Ainda pouco explorados como meio de representaçáo de dados e informaçóes, os objetos físicos baseados em dados devem ser alvo de novas iniciativas à medida que ferramentas de fabricação digital são desenvolvidas e aperfeiçoadas, permitindo a produção de geometrias complexas com poucos recursos. A materialização de dados gera novas possibilidades de leitura e compreensão, pois a percepção passa a ocorrer também através do tato, e passa a ser alterada por fatores como iluminaçáo, temperatura, peso e posição no espaço. A eficácia, a validade e as especificidades desse tipo de representação devem ser temas em breve de novas pesquisas da área.

A investigação do objeto ou suporte físico como forma de representação de dados espaciais nesse trabalho envolve dois objetivos principais. A primeira é referente a finalidade das atividades de extensão univesitária: os dados devem ser transmitidos as comunidades e pesquisadores envolvidos nos projetos, de modo que possam ser utilizados como ferramenta no processo de análise da cidade e no desenvolvimento de proposiçóes e tomadas de decisão. Nesse aspecto, devemos considerar como ocorre a absorção desses dados e qual a eficiência da informação para trazer embasamento às discussóes.

O segundo objetivo é referente ao próprio processo: por se tratar de atividade realizada no âmbito acadêmico, a própria produção das ferramentas deve considerar fatores como o caráter pedagógico dos procedimentos, os recursos disponíveis e sua replicabilidade nesse contexto. Assim, foi valorizada no processo a escolha dos softwares e ferramentas, privilegiando aqueles que pudessem, tanto quanto possível, ser acessados com facilidade e poucos recursos, e cujo próprio funcionamento ou interface tivesse algum aspecto a ser aproveitado no ensino, transmitindo conceitos e procedimentos representativos do uso das tecnologias digitais nessa área.

Nesse ponto deve ser discutido como ocorre o aprendizado do software, para qual nível de usuário sua interface é desenvolvida, a interoperabilidade entre as diversas ferramentas e a necessidade de se conhecer especificidades do funcionamento de cada software.

Tendo a região metropolitana de São Paulo como objeto de estudo, o trabalho propôs a utilizaçáo de técnicas de geoprocessamento, programação e modelagem paramétrica para a construção de um objeto tangível. Ele é baseado em dados de naturezas diversas, retirados de uma pesquisa sobre mobilidade urbana referente à região.

\section{Definição do Objeto}

Para analisar a região metropolitana em função das diretrizes citadas, é proposto um objeto físico que é um mapa tridimensional da regiáo metropolitana de Sáo Paulo. As referências para a construçáo do objeto são os conceitos de data-objects e de superfície estatística. Segundo Gwilt (2012), o data-object é uma interpretação de dados técnicos digitais através da materialização de uma forma, atingindo através desse objeto uma audiência variada, melhorando a compreensão de um determinado conjunto de dados e tornando-os mais acessíveis. A partir dessa definição, propóe-se nesse trabalho a materialização de uma superfície estatística. A superfície estatística, segundo o conceito de Ramos (2005), é obtida através da interpolação dos dados distribuídos no espaço. Essa estimativa gera uma série de valores que podem ser mapeados como parâmetro do deslocamento dos pontos do mapa no eixo z, gerando um volume. Esse volume, representando um conjunto de dados mapeados no espaço, será a base do objeto proposto.

A pesquisa propóe então a busca por formas de sobrepor dados no objeto através de impressão ou projeçóes, inspirando-se na definição de Ware (2004) para o conceito de mapa multivariado. Segundo ele, esse tipo de mapa é um objeto visual no qual uma forma tridimensional representa, através do sombreamento de sua superfície, uma informação, geralmente o relevo de um terreno, e outros tipos de informação são sobrepostas a partir da aplicação de novas camadas. Ele cita as cores e texturas como forma de sobrepor no objeto duas ou mais camadas de informação.

Como fonte dos dados, foi escolhida a pesquisa Origem Destino (OD), realizada pelo metrô de são paulo, por ser a que aborda de forma mais completa o tema da mobilidade urbana para a regiáo. Ela faz um levantamento das viagens realizadas em são Paulo, considerando os diversos modais de transporte. Para isso, a pesquisa divide a regiáo metropolitana em zonas, representando o local de origem e de destino de cada viagem. A zona é a menor unidade territorial para a qual grande parte dos dados levantados estão disponíveis. Para cada zona, além do mapeamento das viagens realizadas, são feitas estimativas da renda das famílias que ali residem, entre outros tipos de dados estatísticos.

Para a produção do protótipo, optou-se por trabalhar com duas categorias de dados presentes na pesquisa. A renda familiar (em reais, por zona da pesquisa) foi escolhida como base para a geração da geometria. Entende-se que é uma categoria importante na comparaçáo com dados de outra natureza, também no que se refere a mobilidade urbana. Com as imagens projetadas poderiam ser criadas formas de relacionar renda familiar e distância dos deslocamentos diários, por exemplo. Já os dados referentes aos deslocamentos pela cidade, que incluem número de viagens de acordo com a zona de partida, zona de origem e modo de transporte, foram a base para a criação de um visualização $2 \mathrm{D}$ interativa a ser posteriormente projetada sobre o objeto base.

O objeto, em sua vista superior, tem como contorno os próprios limites do mapa da regiao metropolitana, criando a percepção da escala do objeto em funçáo de uma forma conhecida. A representação do valor da renda familiar no eixo z se dá com a criação de uma superfície contínua, através da criação de uma malha de pontos onde cada um deles representa o centro de uma zona, e sua posiçáo no eixo vertical o valor correspondente. 


\section{Procedimentos para a Criação do Protótipo}

A proposta inicial do objeto previa duas frentes de ação para sua produção, sendo a primeira a do objeto físico e a segunda referente ao material para projeção, incluindo imagens e plataformas interativas.

Os dados obtidos com a pesquisa foram inicialmente levados para o software GIS TerraView, onde foi possível visualizá-los em forma de mapas e tabelas e criar uma escala de cores conforme a distribuiçáo dos dados da pesquisa. A partir desse procedimento foi possível obter uma prévia do que teríamos como superfície do objeto proposto.

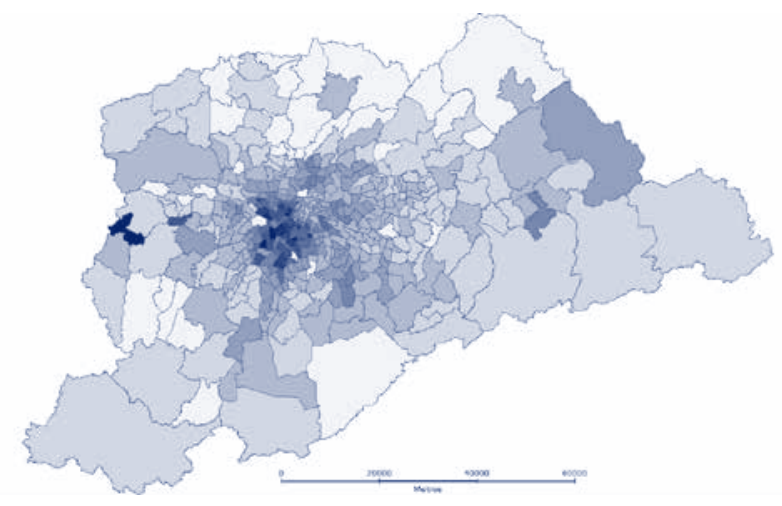

Figura l: Visualizaçẫo dos dados no TerraView: as áres mais escuras representam as maiores médias de renda familiar

\section{Modelagem do Objeto}

Para a geraçáo da forma, os polígonos representando os limites de cada conforme a divisão considerada na pesquisa, presentes num arquivo do tipo shapefile, foram convertidos para o programa de modelagem Rhinoceros através do plug-in Grasshopper, que tem um componente específico para a leitura da geometria de arquivos desse tipo. A tabela contendo os atributos dos polígonos, no caso um numero de identificação e o valor correspondente a média da renda familiar por zona da cidade, foi também importada através desse plugin utilizando-se um leitor de arquivos formato xls.

Para a geração de uma topografia, foram criados pontos como centro geométrico de cada polígono, e esses pontos foram conectados entre eles formando uma malha. Foram acrescentados na malha os pontos do contorno da regiáo metropolitana, de modo a criar uma relaçáo do objeto com a forma do mapa.

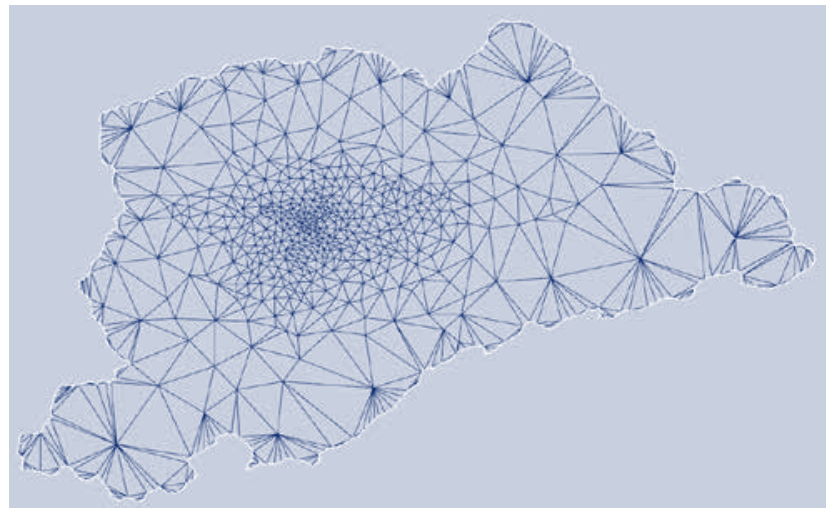

Figura 2: Malha construída no Rhino a partir do centro de cada polígono
Para cada ponto foi feito um deslocamento no eixo Z, cuja distância era proporcional ao valor da renda presente na tabela, na zona correspondente. Assim a malha passava a ser tridimensional, representando na forma de relevo os dados obtidos na pesquisa. Ainda no software Rhino foi criada uma base no formato do objeto, que unida à malha obtida gerou um sólido único, passível de ser exportado para softwares de renderizaçáo e, no formato stl, para máquinas como impressoras 3D.

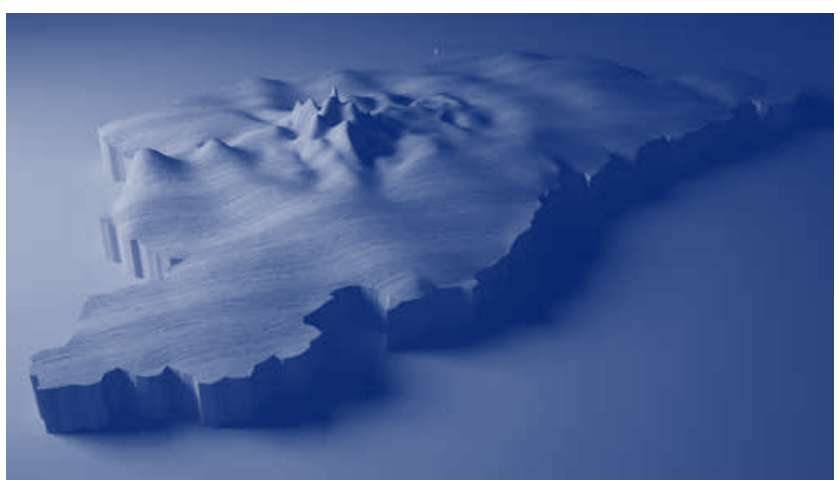

Figura 3 : Imagem renderizada do objeto construído a partir dos dados

\section{Sobreposição de Imagens}

Tendo como objetivo a sobreposição no objeto dos dados diversos da pesquisa, através de projeção, foi proposta a criação de um ambiente interativo. Dada a complexidade das linhas formadas pelas viagens realizadas na região, identificadas na pesquisa, através de uma interface simples baseada no uso do mouse. Dessa forma temos a opçâo de exibir na tela somente viagens referentes somente a uma determinada zona, selecionada através do mouse, simplificando a imagem gerada e direcionando o resultado ao interesse do usuário.

O processo de geração do aplicativo interativo a ser projetado no objeto base consistiu em transferir os dados espaciais referentes a pesquisa Origem Destino ao Processing, um ambiente de programação com variedade de recursos gráficos, relacionando sua geometria às tabelas da pesquisa de modo a obter novos recursos na visibilidade desses dados.

A linguagem Processing possui uma biblioteca de funçôes, chamada Unfolding Maps, que permite a utilizaçáo de mapas interativos como base. Essa biblioteca fornece ferramentas para a leitura de geometrias georreferenciadas e sua representação no sistema de coordenadas WGS84.

Para que essa transferência dos dados entre as plataformas fosse feita, as coordenadas dos polígonos do mapa foram, através do software TerraView, convertidas do sistema de coordenadas UTM Córrego Alegre para WGS84. Esse arquivo foi então exportado com o formato Geo.Json, formato específico de geometrias georreferenciadas compatível com linguagens baseadas em Java, como é o caso do Processing.

Os dados referentes a cada zona foram transformados em tabelas contendo também as coordenadas do centróide de cada polígono, que serviriam de base para o desenho das linhas representando as 
viagens. Cada tabela era referente a um modo de viagem e continha todas as combinaçóes de origem e destino possíveis com o respectivo número de viagens obtido na pesquisa.

Um algoritmo recursivo simples foi codificado no processing de modo que para que cada linha da tabela fosse desenhada no mapa uma linha ligando a coordenada do ponto de origem à coordenada do ponto de destino de determinado tipo de viagem. A espessura dessa linha foi definida como proporcional ao número de viagens entre esses dois pontos, dado também presente em uma das colunas da tabela. A cor das linhas se dava a partir da identificação da tabela de origem. Dada a complexidade do conjunto de informaçóes demonstrada, o usuário do aplicativo seleciona a zona cujos dados ele deseja que sejam mostrados. O Processing gera um aplicativo executável que pode ser aberto em qualquer computador com a tecnologia Java.

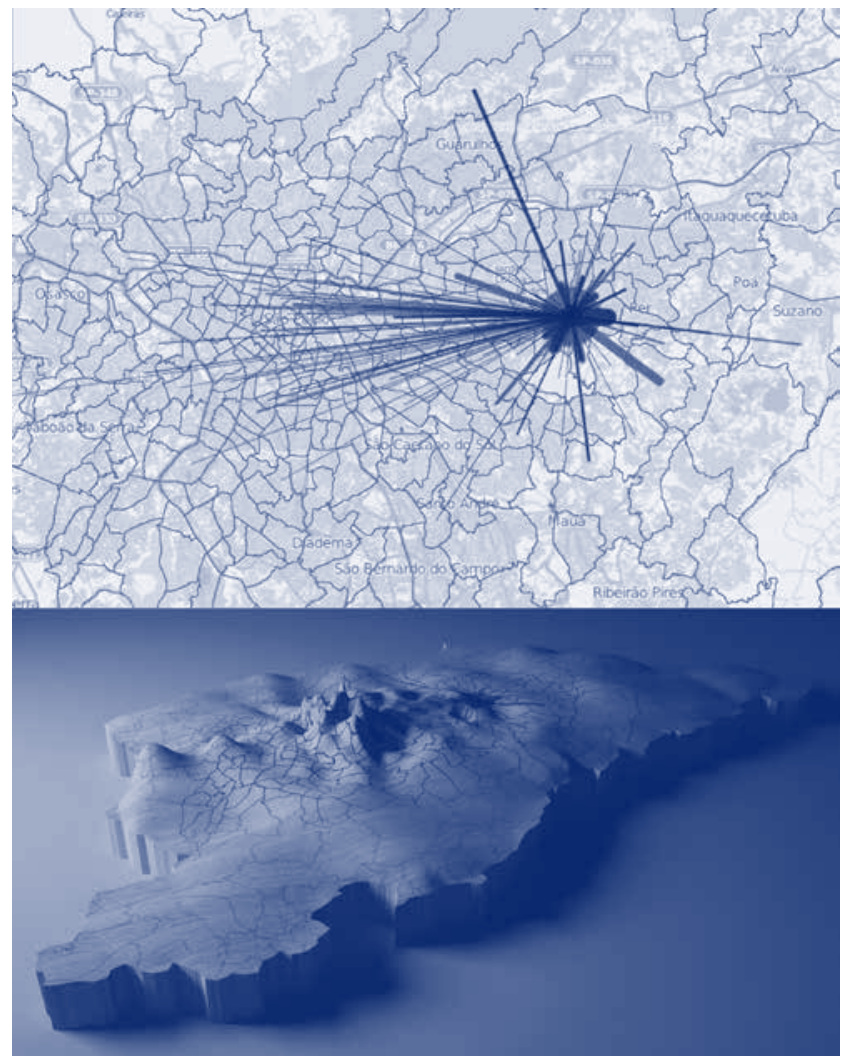

Figura 4: Visualizaçáo das viagens, acima em $2 \mathrm{~d}$ e abaixo projetada sobre o objeto: cada cor de linha representa um modo de transporte, e a espessura indica o número de viagens.

Além do aplicativo desenvolvido, foram simuladas situaçóes com aplicaçóes de outro tipos de imagem. Fotos de satélite podem ser utilizadas para uma aproximaçáo do modelo com a realidade. Ware (2004) coloca que linhas no sentido das curvaturas podem ressaltar a forma quando aplicadas como textura.

As imagens do protótipo virtual renderizadas serviram de base para uma primeira avaliaçáo antes que fosse planejada a prototipagem física do objeto, próxima etapa desse trabalho.

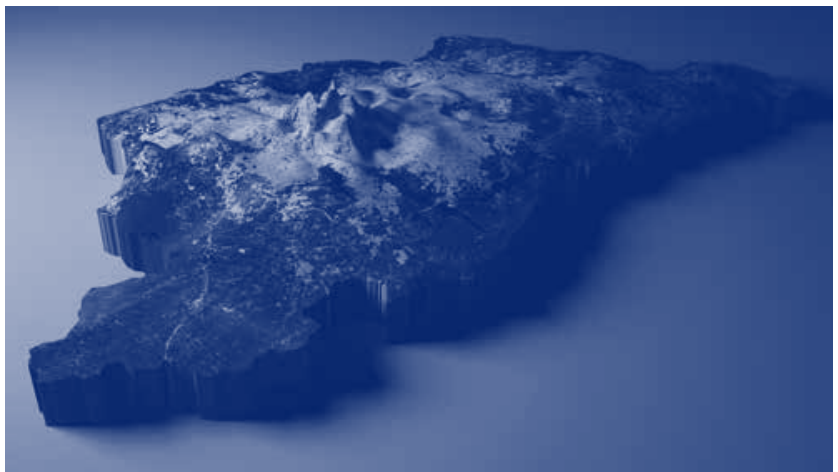

Figura 5: Projeção da foto de satélite sobre o objeto, onde é possível visualizar as áreas de urbanizaçấo consolidada.

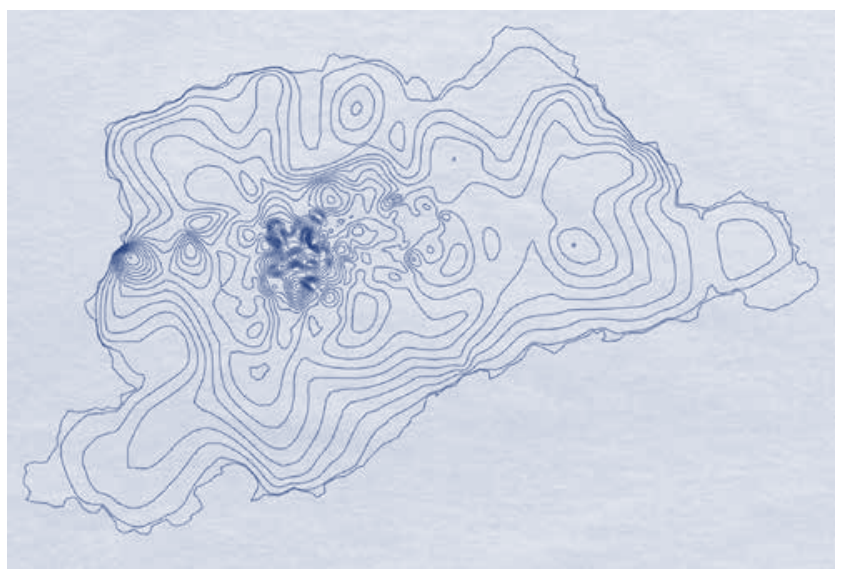

Figura 6: Linhas retiradas das secçốes do volume também podem ser utilizadas sobre o objeto como forma de aumentar a percepçáo do volume

\section{Consideraç̧ões Finais}

Através da análise do processo de definição e representação do objeto, e partindo da experiência obtida com os procedimentos realizados até o momento, foi possível inferir algumas potencialidades e especificidades desse tipo de representação.

A utilidade da ferramenta foi validada como base para discussóes envolvendo as comunidades onde ocorrem projetos de extensão universitária. Alguns aspectos interessantes para a discussão ficam prejudicados devido a escala: para haver uma maior aproximação entre as informaçóes e o cotidiano da comunidade, deve-se trabalhar com escalas menores, onde podem ser observados temas mais tangíveis. Uma opçáo seria trabalhar com objetos diversos simultaneamente, com escalas variadas, buscando pontos de apoio para a transição entre uma escala e outra. O método desenvolvido permite que os mesmos procedimentos sejam utilizados para a produção de objetos referentes a dados de outras naturezas e em outras escalas, com poucas adaptaçóes.

Quanto ao aproveitamento pedagógico, através desse processo seria possível trabalhar com estudantes de graduação os seguintes tópicos:

- fundamentos da modelagem baseada em dados

- conhecimento da interface dos softwares 
- fundamentos de programaçáo

- conceitos de banco de dados e softwares GIS

- ferramentas de renderização

- funcionamento das ferramentas de fabricação digital

- relaçóes entre dados e espaço

- $\quad$ automatização de processos de modelagem e geração de imagem

Em relação à sobreposição de informaçóes distintas, foi constatada uma maior facilidade em transmiti-las de modo simultâneo através desse processo, em comparação com técnicas de visualização $2 \mathrm{~d}$ baseadas em GIS mais tradicionais. Algumas das relaçóes entre dados que podem ter a percepção melhorada incluem por exemplo, no caso do aplicativo interativo, o comprimento do deslocamento ocorrido em função da renda familiar, permitindo desenvolver algumas relaçôes diretas entre os dois tipos de informação. A partir da foto de satélite sobreposta ao modelo, também é possível construir análises entre padróes de ocupação, presença dos rios na cidade, influência de equipamentos urbanos de grande porte, sempre com o pano de fundo de algum tema específico, no caso a renda familiar.

Devemos observar também que o processo tem um viés: a escolha dos dados, das combinaçôes e das escalas tem a capacidade de direcionar a leitura. Por isso é importante o debate acerca do "o que" e do "como" ao construir um objeto desse tipo. Cada caso envolve questóes específicas que pedem a utilização de critérios diferentes.

As avaliaçôes feitas até agora tiveram como base as imagens renderizadas e o próprio modelo $3 \mathrm{~d}$ visualizado em ambiente virtual. Os próximos passos do trabalho incluem o planejamento para fabricação digital, com preparaçấo do arquivo e dos equipamentos para fabricação. A partir de avaliaçóes feitas no uso da ferramenta em trabalhos de campo poderá ser observado de forma mais precisa o modo como ocorre a construçáo de relaçóes entre a vida cotidiana a leitura dos dados.

\section{Referências}

Gwilt, I, Yoxall, A. Sano, K. (2012) Enhancing the understanding of statistical data through the creation of physical objects. In: DUFFY, A, Nagai, Yukari and Taura, Toshiharu. The 2nd International Conference on Design Creativity. UK, Design Society.

Manovich, L (2001).. Information and Form. Retrieved from http:// www.manovich.net/ia/.

Oosterhuis, K. (2002) Programmable Architecture. Torino: L'arcaedizioni,

Ramos, C.S. (2005) Visualização cartográfica e cartografia multimídia: conceitos e tecnologias. São Paulo: Editora UNESP.

Vande Moere, A. (2005) Form Follows data. Retrieved from http:// www.manovich.net/nnm\%20map/form_follows_data.pdf

Ware, C. (2004) Information Visualization. San Francisco: Elsevier. 